\title{
Copolymers and Hybrids Based on Carbazole Derivatives and Their Nanomorphology Investigation
}

\author{
Stefania Aivali ${ }^{1}$, Sofia Kakogianni ${ }^{1}$, Charalampos Anastasopoulos ${ }^{1}$, \\ Aikaterini K. Andreopoulou 1,2® and Joannis K. Kallitsis 1,2,*(i) \\ 1 Department of Chemistry, University of Patras, University Campus, Rio-Patras GR26504, Greece; \\ aivali.s@upnet.gr (S.A.); skakogianni@upatras.gr (S.K.); xanastasop@upatras.gr (C.A.); \\ andreopo@upatras.gr (A.K.A.) \\ 2 Foundation for Research and Technology Hellas/Institute of Chemical Engineering \\ Sciences (FORTH/ICE-HT), Platani Str., Patras GR26504, Greece \\ * Correspondence: j.kallitsis@upatras.gr; Tel.: +302610-962957
}

Received: 19 December 2018; Accepted: 18 January 2019; Published: 22 January 2019

check for updates

\begin{abstract}
Oligomers of the low-band-gap PCDTBT polymer, based on either 3,6 or 2,7 carbazole units, were modified with vinyl $\omega$-chain end functionalities. The vinyl-functionalized oligomers were used as comonomers in free radical polymerizations with quinoline-based monomers such as 6-vinylphenyl-(2-pyridinyl)-4-phenyl-quinoline (vinyl-QPy), and 6-vinylphenyl-(2-perfluorophenyl)-4-phenyl quinoline (vinyl-5FQ). The co-polymeric materials bearing the vinyl-QPy moiety were developed as potential compatibilizers in polymer electron donor-fullerene acceptor blends for non-covalent interactions with the fullerene part. The co-polymeric materials bearing the vinyl-5FQ moiety were developed for the covalent attachment of carbon nanostructures; specifically, $\mathrm{PC}_{61} \mathrm{BM}$. Both copolymers and hybrids, after thorough purification, were characterized in terms of their spectroscopic and optical properties as well as their ability to form nanophased separated films as such, or as additives at various percentages into PCDTBT: $\mathrm{PC}_{71}$ BM blends.
\end{abstract}

Keywords: vinyl functionalized PCDTBT; PCDTBT: $\mathrm{PC}_{71} \mathrm{BM}$ blends; fullerenes; hybrid semiconducting polymers; nanomorphology

\section{Introduction}

In recent years, organic photovoltaics (OPVs) based on conjugated polymers have come to be considered a promising route for renewable energy production devices due to their advantages, such as their low cost, flexibility, light weight and their offering facile coverage of large-scale areas of various shapes, compared to silicon-based solar cells [1-3]. So far, organic solar cells composed of a binary mixture of a polymeric electron donor and a fullerene derivative as the electron acceptor (Bulk Heterojunction OPVs) have achieved power conversion efficiencies (PCEs) of over $10 \%$ [4-7]. Some of the most promising systems for these devices are the P3HT:IC ${ }_{60} \mathrm{BA}$ [8-10] and the PCDTBT:PC ${ }_{71}$ BM [11,12], from both efficiency and stability points of view. To further improve the efficiencies of OPVs, there are many factors that need to be considered, such as the development of efficient electron donors, combined with the proper electron acceptors [13-15] and the control and stabilization of the morphology of the active layer [16-20].

The functionalization of the semiconducting polymers used as electron donors has opened the route to the formation of more effective nanophase-separated active layers, which, moreover, could be used to create alternative copolymers [21-24] for the purpose of affording not only efficient, but also stable, OPVs under a variety of time and environmental conditions. The introduction 
of various functional units onto semiconducting polymers, either as side chains or at the $\alpha$ and/or $\omega$-end positions of the polymeric chains, allows a variety of approaches for the formation of complex macromolecular architectures or even hybrid structures. Such modifications on the semiconducting polymeric chains enable the covalent attachment of a semiconducting polymer onto carbon nanostructures, creating hybrid materials that are expected, and in many cases have indeed revealed, combined properties, altering and fine-tuning the morphology and nanophase separation of the pure component blends [25-30]. Another approach for the formation of hybrid structures is the development of non-covalent interactions between a molecular dispersant (in most cases a pyridine unit) and fullerene species. Such interacting species can be incorporated either into copolymers, or onto the molecular additives of the active layer binary blend. Ikkala et. al. reported the synthesis of a rod-coil copolymer bearing PS/P4VP units, which interacts with the fullerenes towards the formation of self-assembling domains [31]. In that study, the electron-donating pyridine moiety forms charge-transfer complexes with the electron-accepting $\mathrm{C}_{60}$ molecules in both bulk and spin-casted films, leading to improved nanophase separation. The research group of Hadziioannou [32] introduced a P3HT-b-P4VP block copolymer as a nanostructuring agent in the polymer/fullerene blend, and a significant enhancement of the efficiency was observed. The addition of pyridine units directly at the end or side positions of polymeric electron donors most probably leads to their incorporation at the donor/acceptor interface, thus influencing the crystallinity of the fullerene species and hence increasing the power conversion efficiency of the device [33,34].

Herein, copolymers and hybrids based on low-band-gap oligomers of the poly

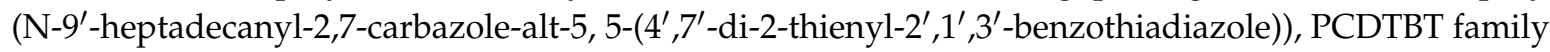
are reported. In particular, vinyl end functionalized low-band-gap PCDTBT oligomers are used as macro-co-monomers in free radical polymerizations with two different electron-accepting quinoline-bearing vinyl monomers. In the first case, copolymers bearing the phenyl- (2-pyridinyl) -4-phenyl-quinoline (QPy) moiety were developed as potential stabilizers/compatibilizers of PCDTBT:PC $71 \mathrm{BM}$ binary blends in order to employ the non-covalent interactions of the fullerene part with the quinoline-pyridine units. In the second case, copolymers bearing the phenyl- (2-perfluorophenyl) -4-phenyl- quinoline (5FQ) moiety were developed, since the perfluorophenyl groups can covalently attach onto the $\mathrm{sp}^{2}$ hybridized surface of carbon nanostructures. This latter approach was recently demonstrated by our group, and allows the direct connection of the semiconducting species onto the carbon nanostructures, creating hybrid materials in which the properties of the constituent organic and carbon nanostructure entities are influenced and/or combined [35].

\section{Materials and Methods}

\subsection{Materials}

PCDTBT was purchased from Solaris Chem. Inc. (QC, Canada) PC[60]BM 99\% and PC[70]BM 99\% were purchased from Solenne b.v. Groningen, The Netherlands. Tetrahydrofuran was purchased from Aldrich (Sigma-Aldrich Chemie GmbH, Taufkirchen, Germany) and was distilled with benzophenone and metallic sodium (THF (dry)). All other solvents and reagents were purchased from Aldrich (Sigma-Aldrich Chemie GmbH, Taufkirchen, Germany) or Alfa Aesar (Thermo Fisher (Kandel) GmbH Postfach, Karlsruhe, Germany) and were used without further purification unless otherwise stated. 6-Vinylphenyl-(2-pyridinyl)-4-phenyl-quinoline (vinyl-QPy) [36], 6-vinylphenyl-(2-perfluorophenyl)-4-phenyl-quinoline (vinyl-5FQ) [37], 4,7-di-2-thienyl-2,1,3-benzothiadiazole (di-thien-BTZ) [38,39], 4,7-di-(5-bromothiophene-2-yl-2,1,3 -benzothiadiazole (di-Br-di-thien-BTZ) [40], 2,7-dibromo- $N$-heptadecan-9-yl-carbazole (di-Br-HDcarbazole) [41], 2,7-di(4,4,5,5-tetramethyl-1,3,2-dioxaborolan)-N-heptadecan-9-yl-carbazole (di-boronic ester-HD-carbazole) [41], 3,6-dibromo- $\mathrm{N}$-2-ethylhexyl-carbazole (di-Br-EH-carbazole) [42], 3,6-bis $\left(4^{\prime}, 4^{\prime}, 5^{\prime}, 5^{\prime}\right.$-tetramethyl-1' $3^{\prime}, 2^{\prime}$-dioxaborolan-2'-yl)-N-9'-(ethylhexyl) carbazole [43] and the catalyst 
palladium (II) tetrakis triphenyl phosphine $\left(\mathrm{Pd}\left(\mathrm{PPh}_{3}\right)_{4}\right)$ [44] were synthesized according to published procedures.

\subsection{Characterization}

${ }^{1} \mathrm{H},{ }^{19} \mathrm{~F}$ Nuclear Magnetic Resonance (NMR) spectra were recorded on a Bruker Advance (Bruker BioSpin GmbH, Magnet Division, Karlsruhe, Germany) DPX 400.13, 376.5 and $40.55 \mathrm{MHz}$ spectrometer, respectively, with $\mathrm{CDCl}_{3}$ as solvent containing TMS as internal standard.

Gel permeation chromatography (GPC) measurements were carried out using a Polymer Lab chromatographer (Agilent Technologies, Santa Clara, CA, USA) equipped with two PLgel $5 \mu \mathrm{m}$ mixed columns and a UV detector, using $\mathrm{CHCl}_{3}$ as eluent with a flow rate of $1 \mathrm{~mL} / \mathrm{min}$ at $25^{\circ} \mathrm{C}$ calibrated versus polystyrene standards.

Attenuated Total Reflectance (ATR) spectra were recorded on a "Bruker Optics' Alpha-P Diamond ATR Spectrometer of Bruker Optics GmbH" (Ettlingen, Germany).

Thermogravimetric analysis (TGA) was carried out on $\sim 8 \mathrm{mg}$ samples contained in alumina crucibles in a Labsys TM TG apparatus of Setaram (Caluire, France) under nitrogen and at a heating rate of $10^{\circ} \mathrm{C} / \mathrm{min}$

UV-Vis spectra were recorded using a Hitachi U-1800 spectrophotometer (Hitachi High-Technologies Europe $\mathrm{GmbH}$, Mannheim, Germany). Continuous wave photoluminescence was measured on a Perkin Elmer LS50B spectrofluorometer (Waltham, MA, USA). All UV-Vis and PL measurements were performed in air using quartz cuvettes and flat quartz substrates for the examination of solutions and films, respectively.

Transmission electron microscopy (TEM) measurements were performed on a JEOL JEM2100 (Tokyo, Japan) operating at $200 \mathrm{kV}$. Sample preparation for TEM examination involved the drop-casting of diluted in $o$-DCB solutions and the removing the excess of the solvent with filter paper onto $3 \mathrm{~mm}$ carbon coated copper grids (Electron Microscopy Sciences, Hatfield, PA, USA) and were dried in air for 2 days.

The detailed experimental procedures for all the synthesized materials are given in the Supplementary Materials section.

\section{Results}

\subsection{Synthesis of Functionalized Vinyl PCDTBT-Based Macromonomers}

Oligomers of the poly(carbazole-alt-benzothiadiazole)-PCDTBT family were synthesized via Suzuki cross-coupling polymerization reaction and were modified in situ at the $\omega$-end positions of the polymer's backbone with functional groups (see Scheme 1). To investigate the influence of the carbazole derivative onto the polymer's properties, we used either the 3,6 or the 2,7-carbazole derivative. Firstly, in order to get PCDTBT oligomers of increased solubility, we employed the 3,6-carbazole monomer, which leads to more soluble and less rigid polymeric chains [45,46]. The desired monomer of di-Br-di-thien-BTZ was synthesized according to the procedures in the literature [39-41]. The final PCDTBT-type oligomers were synthesized via Suzuki cross-coupling using the catalyst:base system $\mathrm{Pd}\left(\mathrm{PPh}_{3}\right)_{4}: \mathrm{Et}_{4} \mathrm{NOH} 20 \%$ [47]. At the last step of the polymerization reaction, 4-vinylphenylboronic acid and bromobenzene were added successively to the mixture to introduce polymerizable double bonds at the end position of the polymer and a phenyl group at the other end, creating monofunctional, "active" polymers that could be used as macromonomers in free radical polymerizations (FRP) combined with other vinyl-monomers. Due to structural differences of the 3,6- carbazole to the 2,7- carbazole monomers, and in order to control the molecular weight leading to oligomers that are soluble enough and could be used afterward in free radical polymerizations, different polymerization periods were employed in these two cases, as shown in Table S2. In both cases, the crude vinyl functionalized PCDTBT-type oligomers were precipitated into methanol and further purified and fractionated via Soxhlet extraction with acetone and cyclohexane to 
remove salts, catalyst and any residual monomers [48] and finally tetrahydrofuran, so as to receive polymeric fractions, useful for the next FRP steps. To receive the higher molecular weights of both 3,6- and 2,7-vinyl functionalized polymers and at the same time to keep the double bonds "alive", the insoluble fraction obtained after the THF extract, was heated at temperatures no higher than $80{ }^{\circ} \mathrm{C}$ with chlorobenzene, (CB), for $6 \mathrm{~h}$ and then filtrated at $60^{\circ} \mathrm{C}$.

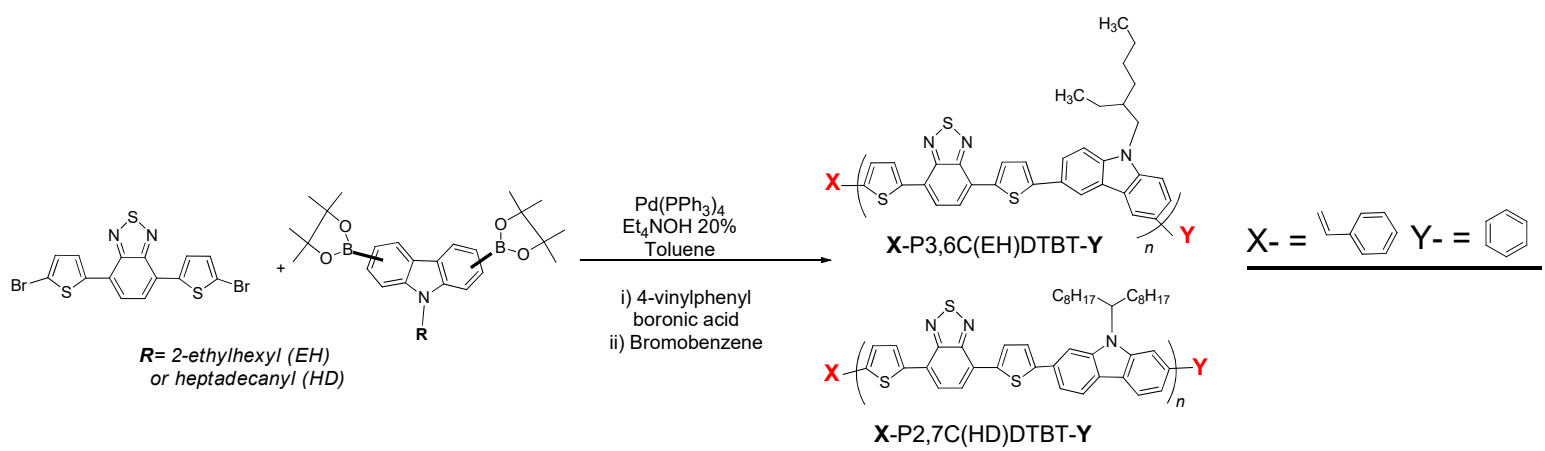

Scheme 1. General synthetic procedure for $\omega$-vinyl functionalized PCDTBTs.

The successful introduction of the end double bonds was confirmed through ${ }^{1} \mathrm{H}$ NMR (Figure 1 for the THF fraction of the oligomers) and ATR (Figure 2 and Figure S1 for the THF and the CB fractions of the oligomers). From the ${ }^{1} \mathrm{H}$ NMR spectrum of P3,6C(EH)DTBT-vinyl, peaks at 5.26, 5.76 and $6.72 \mathrm{ppm}$ are attributed to the double bonds at the end position of the polymeric chain. Unfortunately, in the ${ }^{1} \mathrm{H}$ NMR spectrum of P2,7C(HD)TBT-vinyl the respective peaks were not detectable due to the higher molecular weight of the polymer and its lower solubility in $\mathrm{CDCl}_{3}$. Both P3,6C(EH)DTBT and P2,7C(HD)DTBT end-vinyl functionalized oligomers' ATR spectra were compared to the commercial PCDTBT. Besides the characteristic bands of the PCDTBT backbone, a band at $\sim 960 \mathrm{~cm}^{-1}$ appears for vinyl-functionalized macromonomers, which is attributed to the end double bonds.

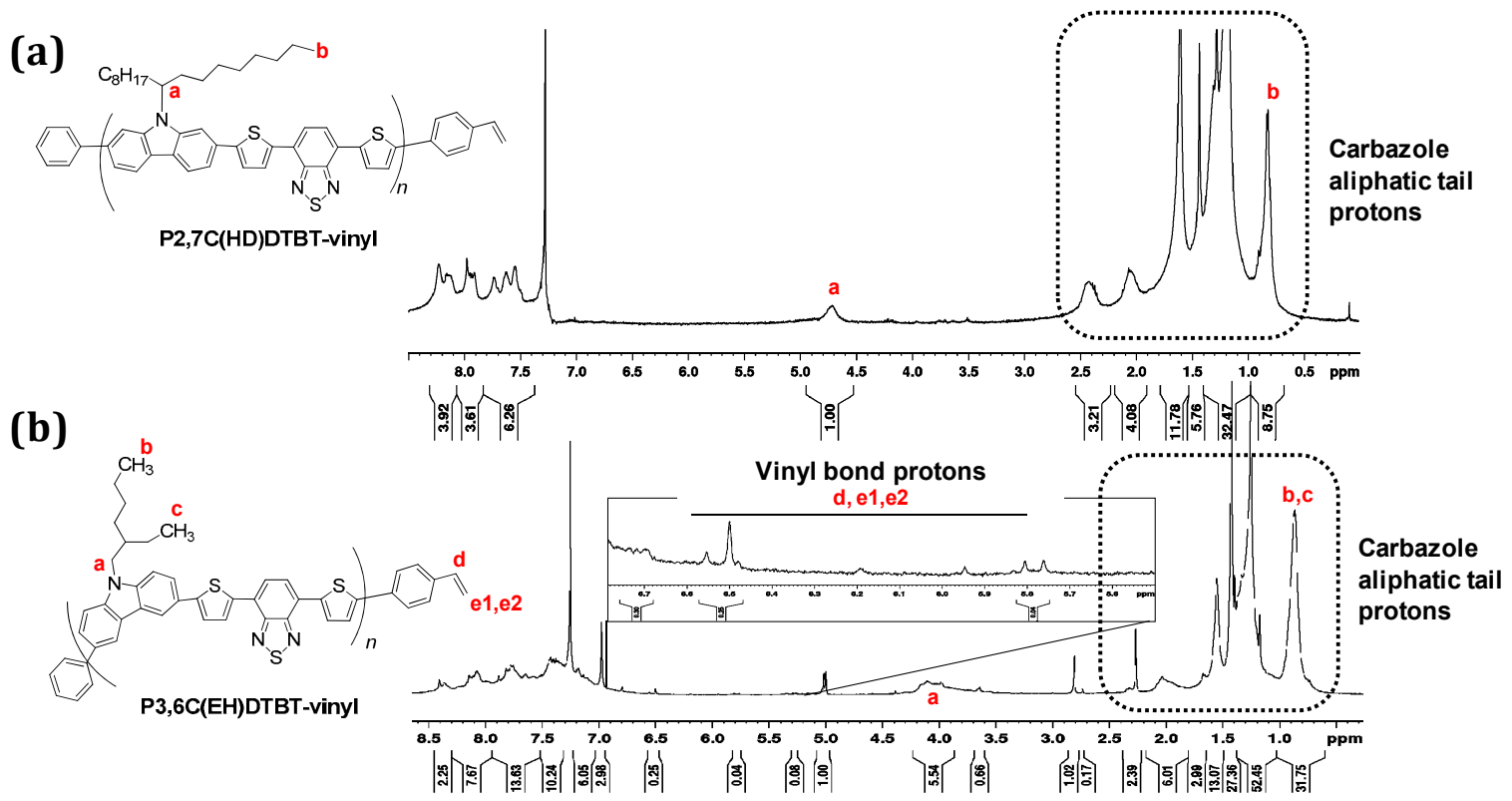

Figure 1. (a) ${ }^{1} \mathrm{H}$ NMR spectrum of $\mathrm{P} 2,7 \mathrm{C}(\mathrm{HD}) \mathrm{DTBT}$-vinyl in $\mathrm{CDCl}_{3}$ and (b) ${ }^{1} \mathrm{H} \mathrm{NMR}$ spectrum of $\mathrm{P} 3,6 \mathrm{C}(\mathrm{EH}) \mathrm{DTBT}-\mathrm{vinyl}$ in $\mathrm{CDCl}_{3}$. 

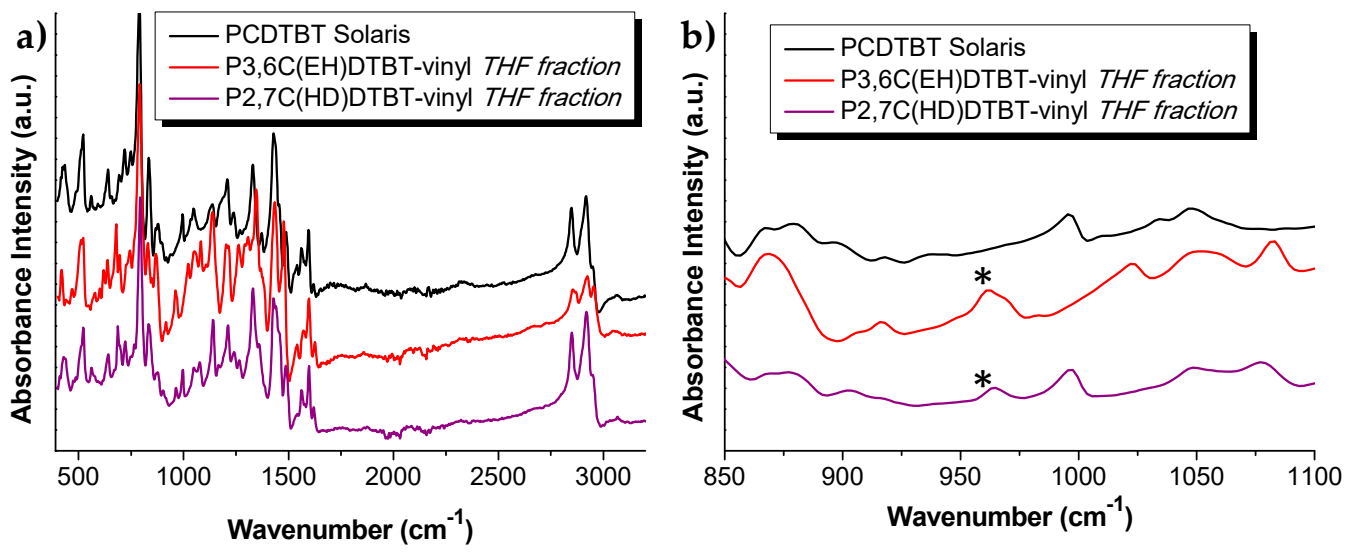

Figure 2. (a) ATR spectra of commercial PCDTBT, P3,6C(EH)DTBT-vinyl and P2,7C(HD)DTBT-vinyl THF fractions. (b) Enlarged region of the ATR spectrum from 850 to 1100 wavenumbers. The asterisks $\left(^{*}\right)$ in Figure 2b, indicate the peaks owing to the $\omega$-end double bonds.

\subsection{Synthesis of PCDTBT-Quinoline Copolymers}

The above-synthesized vinyl-functional oligomers of the poly(carbazole-alt-benzothiadiazole) -PCDTBT family were employed in free radical polymerizations (FRP) with vinyl-quinoline-based monomers, as shown in Scheme 2.

The monomer 6-vinylphenyl-(2-pyridinyl)-4-phenyl-quinoline (vinyl-QPy) was copolymerized via FRP with both the 3,6-carbazole- and the 2,7-carbazole-bearing PCDTBT macromonomers, affording the P3,6C(EH)DTB-PQPy and P2,7C(HD)DTBT-PQPy copolymers, respectively. The quinoline-pyridine unit was selected in order to create copolymers that could interact non-covalently with the fullerene electron acceptors of the active layer blends.

On the other hand, copolymers bearing PCDTBT and the perfluorophenyl quinoline unit were synthesized using the 3,6-carbazole-carrying PCDTBT macromonomer (P3,6C(EH)DTBT) and the 6-vinylphenyl-(2-perfluorophenyl)-4-phenyl quinoline monomer. The perfluorophenyl group was specifically selected in this case, since it can be transformed to an azide and covalently attach onto fullerene species, affording hybrid copolymeric materials [35]. Although the copolymer P3,6C(EH)DTBT-P5FQ was successfully synthesized, attempts to prepare the respective copolymer based on the 2,7 carbazole derivative P2,7C(HD)DTBT were unsuccessful, since the product could not be isolated in workable yield.

In all cases, the vinyl-functionalized PCDTBT macromonomers were copolymerized via FRP with the respective vinyl-quinoline derivatives at a 1:8 weight ratio (PCDTBT macromonomer:vinyl-quinoline derivative) using AIBN as the initiator in a solvent mixture of THF/DMF, forming the desired PCDTBT-quinoline copolymers. The crude products were extensively purified by washing with various solvents such as methanol, ethyl acetate and diethyl ether in order to ensure the successful removal of any unreacted monomers. In Table 1, the theoretical and experimental ratio of PCDTBT:quinoline for the copolymers M1-M5 are presented. 


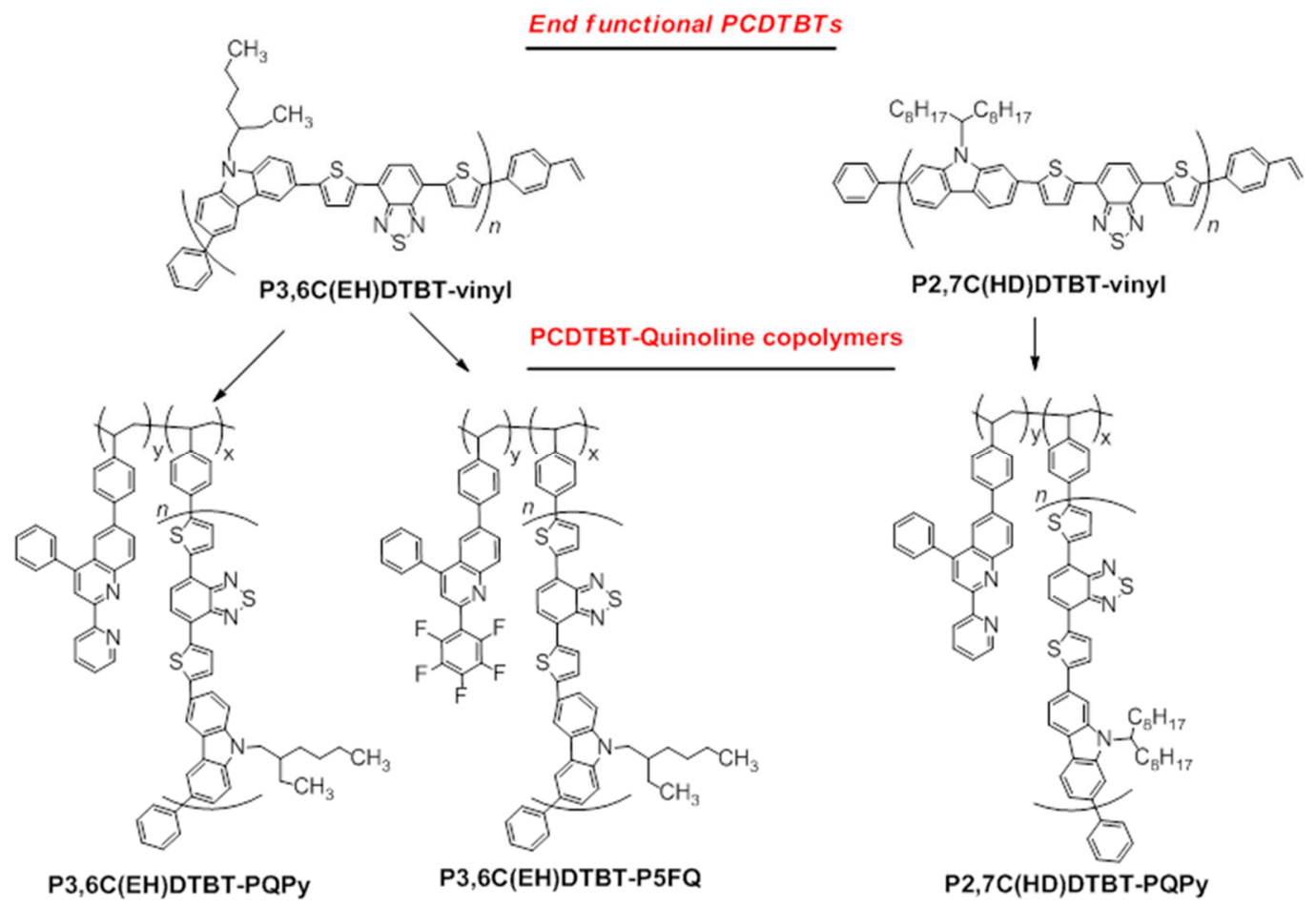

Scheme 2. Synthesis of PCDTBT-quinoline-based copolymers.

From the ${ }^{1} \mathrm{H}$ NMR spectra of the copolymers, (Figure 3), the absence of any peaks that could be attributed to double bonds in combination to the observation of well-resolved characteristic peaks of the quinoline groups at $\sim 6.9-6.3 \mathrm{ppm}$ and of the PCDTBT moiety at $\sim 4.2 \mathrm{ppm}$, confirmed the successful copolymerization of the two moieties. Aside from these, broad peaks attributed to both the quinoline and PCDTBT blocks of the copolymers at $7.3-8.8$ ppm can be observed. From integration of the peak at $4.2 \mathrm{ppm}$, owing to the ethylhexyl methylene protons or the heptadecanyl methane protons of the carbazole units, respectively, and of the peaks at 6.3-6.9 ppm owing to aromatic protons of the quinoline monomers [35,37], the ratio of PCDTBT to the quinoline blocks was calculated. For the P3,6C(EH)DTBT-P5FQ copolymer, ${ }^{19} \mathrm{~F}$ NMR analysis was also performed, which is depicted in the insert of Figure 3, confirming the three different types of fluorine atoms present at the final copolymer due to the P5FQ block. The ATR spectra of the copolymer, together with the spectra of the initial monomers, (Figure S2), also confirm the absence of double bonds and the coexistence of peaks owing to both the copolymer blocks. 


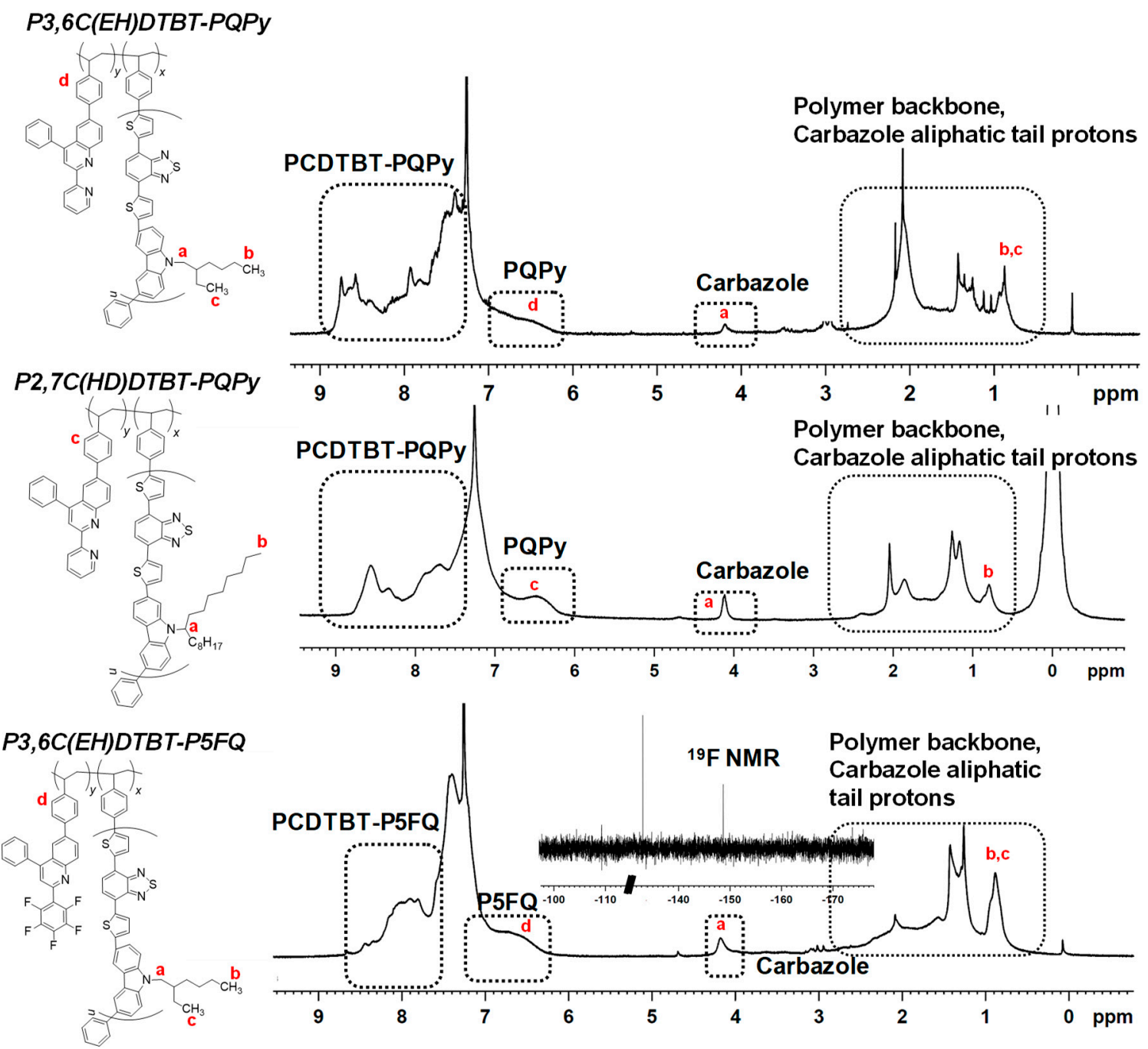

Figure 3. ${ }^{1} \mathrm{H}$ NMR spectra of the PCDTBT-Quinoline copolymers in $\mathrm{CDCl}_{3}$.

In Table 1, the PCDTBT-quinoline theoretical weight percent ratio together with the experimentally found percent ratio calculated from ${ }^{1} \mathrm{H}$ NMR spectra are presented. It is obvious that in some cases (e.g., copolymers M1, M2, M5), a fairly good comparison between the theoretical and experimental weight percent ratios of PCDTBT to QPy units is observed. In other cases, (e.g., copolymers M3, M4), a significant discrepancy is observed, which can be attributed to the possible formation of vinyl-quinoline oligomers that are effectively removed during the purification process as supported by the GPC analysis using different UV detection wavelengths, namely, 254 and $540 \mathrm{~nm}$, where the quinolines and the PCDTBT segments are absorbed, respectively. SEC characterization was performed for all synthesized copolymers with a UV detector both at $254 \mathrm{~nm}$ and $540 \mathrm{~nm}$ wavelengths, at which the quinoline and the PCDTBT blocks, respectively, present their maximum absorbance. The results shown in Table 2 provide the starting molecular weights of the PCDTBT macromonomers and the molecular weights obtained for the corresponding copolymers. All copolymers presented similar Mn and Mw values, as detected at the two wavelengths of 254 and $540 \mathrm{~nm}$, respectively, indicating successful copolymerization and excluding any scenario of homopolymer blends instead of copolymers. We should also point out that the molecular weight of the vinyl-PCDTBT derivative plays an important role on the molecular weight of the final PCDTBT-quinoline copolymer. More specifically, in the case of oligomers isolated from the THFfractions, the final ratio of the respective block into the copolymer was found low. However, due to the complexity of the structure and specifically to the bearing quinoline pyridine units that probably 
interact with the columns' packing material, the characterization through SEC could only provide indicative results. GPC characterization of PCDTBT-P5FQ copolymer and vinyl PCDTBT using the two detectors at 254 and $540 \mathrm{~nm}$ is presented in Figure S3.

Table 1. Theoretical and Experimental Ratio of PCDTBT:Quinoline for the copolymers M1-M5.

\begin{tabular}{|c|c|c|c|c|c|}
\hline \multirow[b]{2}{*}{ Copolymer } & \multirow{2}{*}{$\begin{array}{l}\text { PCDTBT-Quinoline } \\
\text { Theoretical wt\% Ratio }\end{array}$} & \multicolumn{2}{|c|}{ Peak Integrals of ${ }^{1} \mathrm{H}$ NMR } & \multirow{2}{*}{$\begin{array}{c}\text { molar } \% \text { Ratio } \\
\text { Calculated } \\
\text { from }{ }^{1} \mathrm{H} \text { NMR }\end{array}$} & \multirow{2}{*}{$\begin{array}{c}\text { wt. \% Ratio } \\
\text { Calculated } \\
\text { from }{ }^{1} \mathrm{H} \text { NMR }\end{array}$} \\
\hline & & $\begin{array}{l}\text { 6.95-6.3 ppm } \\
\text { 2H-PQuinoline }\end{array}$ & $\begin{array}{c}4.3-4.1 \mathrm{ppm} \\
2 \mathrm{H}-\mathrm{carbazole}\end{array}$ & & \\
\hline M1 & $11 / 89$ & 3.778 & 0.022 & $5 / 95$ & $7 / 93$ \\
\hline M2 & $11 / 89$ & 0.555 & 0.026 & $5 / 95$ & $9 / 91$ \\
\hline M3 & $11 / 89$ & 5.690 & 1.000 & $15 / 85$ & $24 / 76$ \\
\hline M4 & $11 / 89$ & 0.352 & 0.090 & $20 / 80$ & $23 / 77$ \\
\hline M5 & $11 / 89$ & 0.700 & 0.040 & $5 / 95$ & $6 / 94$ \\
\hline
\end{tabular}

Table 2. Feed ratio and GPC results for the copolymers P3,6C(EH)DTBT-PQPy P2,7C(HD)DTBT-PQPy and $\mathrm{P3}, 6 \mathrm{C}(\mathrm{EH}) \mathrm{DTBT}-\mathrm{P} 5 \mathrm{FQ}$ at 254 and $540 \mathrm{~nm}$.

\begin{tabular}{|c|c|c|c|c|c|c|c|c|}
\hline Copolymer & $\begin{array}{c}\text { Mn } \\
\text { PCDTBT }\end{array}$ & $\begin{array}{c}\text { PCDTBT/Quinoline } \\
\% \text { molar ratio } \\
\text { via }^{1} \mathrm{H} \text { NMR }\end{array}$ & \multicolumn{3}{|c|}{ GPC@ 254 nm } & \multicolumn{3}{|c|}{ GPC@540 nm } \\
\hline & & & & & & \multicolumn{3}{|c|}{ PQPy-based copolymers } \\
\hline P3,6C(EH)DTBT-PQPy (M1) & 2100 & $5 / 95$ & 3500 & 4100 & 1.17 & 3650 & 4000 & 1.1 \\
\hline & & & & & & \multicolumn{3}{|c|}{ P5FQ-based copolymers } \\
\hline P3,6C(EH)DTBT-P5FQ (M4) & 2100 & $20 / 80$ & 4900 & 6100 & 1.2 & 5600 & 6700 & 1.2 \\
\hline P3,6C(EH)DTBT-P5FQ (M5) & 2800 & $5 / 95$ & 8200 & 12700 & 1.55 & 7700 & 12000 & 1.56 \\
\hline
\end{tabular}

The results included in Tables 1 and 2 can be used for the estimation of the molecular weight of the copolymers. More specifically, from the proton integrals and the calculation of the copolymers' MW from the ${ }^{1} \mathrm{H}$ NMR spectra, it is obvious that in all the copolymers, at least one PCDTBT macromonomer is attached to each polymeric backbone, while in some cases, even two PCDTBT macromonomers are present. This is also supported by the fact that the GPC traces detected at 254 and $540 \mathrm{~nm}$ are similar, showing that at least one PCDTBT macromonomer is combined with the quinoline units in the copolymers. Based on that assumption, and taking into consideration the ratio of PCDTBT to the quinoline units calculated from the ${ }^{1} \mathrm{H}$ NMR spectra, the real MWs of the copolymers can be estimated, and they are in the range of 38 to $49 \mathrm{kDa}$. These are an order of magnitude higher than the copolymers' MWs found via GPC, which is attributed to the strong interactions of the quinoline moieties with the stationary phase of the GPC columns.

\subsection{Optical Characterization of Copolymers}

The optical properties of the different PCDTBT copolymers synthesized (M1-M5, see Table 2) and of the starting vinyl-quinoline monomers were investigated in solutions, and the obtained results are given in Figure $4 a-c$, respectively. In Figure S4, the absorbance spectra of vinyl PCDTBT macromonomers in $o$-DCB solutions are also presented. The UV-Vis spectra of the copolymers in $o$-DCB solutions show the coexistence of the quinolines' absorption bands and of the PCDTBT blocks. Copolymers bearing the perfluorophenyl-quinoline moiety present an absorption maximum at $330 \mathrm{~nm}$, whereas copolymers bearing the pyridinylphenyl-quinoline show a red-shifted absorption band at $340 \mathrm{~nm}$. Also, a second absorption maximum was observed in the copolymers' case at 500-550nm, owing to the PCDTBT block. A difference in the absorption maximum was observed 
due to the different molecular weights of the PCDTBT macromonomer employed for the copolymers' synthesis M1-M5. Particularly, for higher MW of the initial PCDTBT macromonomer, a more red-shifted absorption peak at $\sim 550 \mathrm{~nm}$ is observed, as shown in Figure 4.

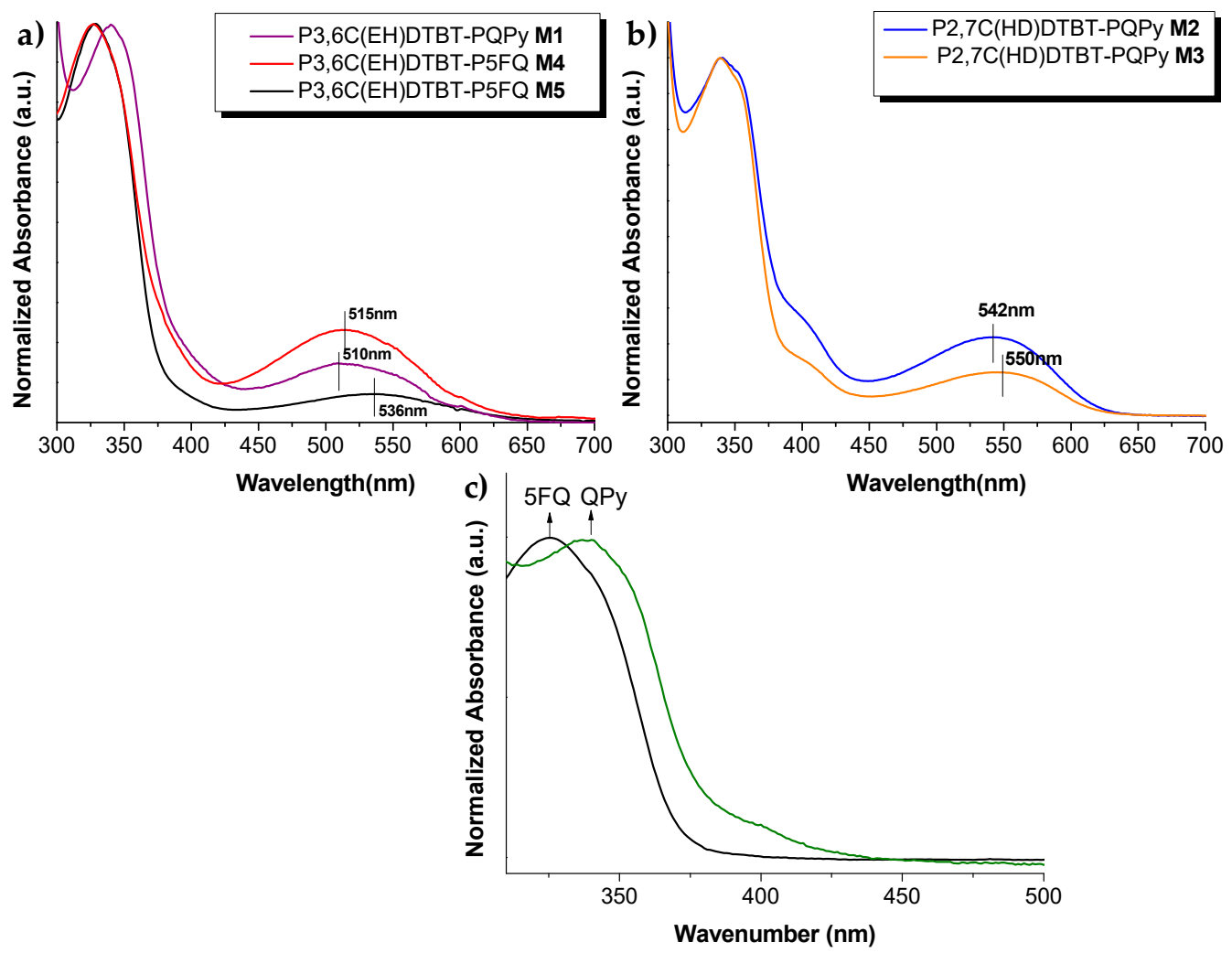

Figure 4. Normalized absorption spectra of (a) 3,6-carbazole-based copolymers M1, M4, M5 in $o$-DCB solutions and their maximum absorbance; (b) 2,7-carbazole-based copolymers M2, M3 in $o$-DCB solutions and their maximum absorbance; (c) absorption spectra of 6-vinylphenyl-(2perfluorophenyl)-4-phenyl quinoline and 6-vinylphenyl-(2-pyridinyl)-4-phenyl-quionoline in $o$-DCB solutions.

\subsection{Blends of PCDTBT:PC ${ }_{71} B M$ with PCDTBT-PQPy Copolymers}

The synthesized copolymers were studied as additives in mixtures of PCDTBT:PC 71 BM 1:1 wt $\%$ ratio. In Table 3, the composition of the blends obtained from o-DCB solutions are presented.

Table 3. Composition of the different blends studied.

\begin{tabular}{|c|c|c|}
\hline Blend & PCDTBT:PC ${ }_{71}$ BM wt. \% & Copolymer wt. $\%$ \\
\hline \multicolumn{3}{|c|}{$P 3,6 C(E H) D T B T-P Q P y(M 1)$} \\
\hline 8 & 100 & 0 \\
\hline 9 & $47,5: 47,5$ & 5 \\
\hline 10 & $45: 45$ & 10 \\
\hline 11 & $40: 40$ & 20 \\
\hline
\end{tabular}


Table 3. Cont.

\begin{tabular}{|c|c|c|}
\hline Blend & PCDTBT:PC ${ }_{71}$ BM wt. \% & Copolymer wt. $\%$ \\
\hline \multicolumn{3}{|c|}{$P 2,7 C(H D) D T B T-P Q P y(M 2)$} \\
\hline 12 & $47,5: 47,5$ & 5 \\
\hline 13 & $45: 45$ & 10 \\
\hline 14 & $40: 40$ & 20 \\
\hline
\end{tabular}

The UV-Vis spectra in film form of the blends 2-4 (Figure 5) presented the same absorbance bands as the PCDTBT:PC 71 BM blend. Upon excitation at $400 \mathrm{~nm}$, no remarkable difference could be observed. Upon excitation at $570 \mathrm{~nm}$, a slightly increased photoluminescence peak was observed for blends bearing $5 \%$ and $10 \%$ of the copolymer, whereas a lower photoluminescence peak was observed for the blend bearing $20 \%$ of the copolymer.

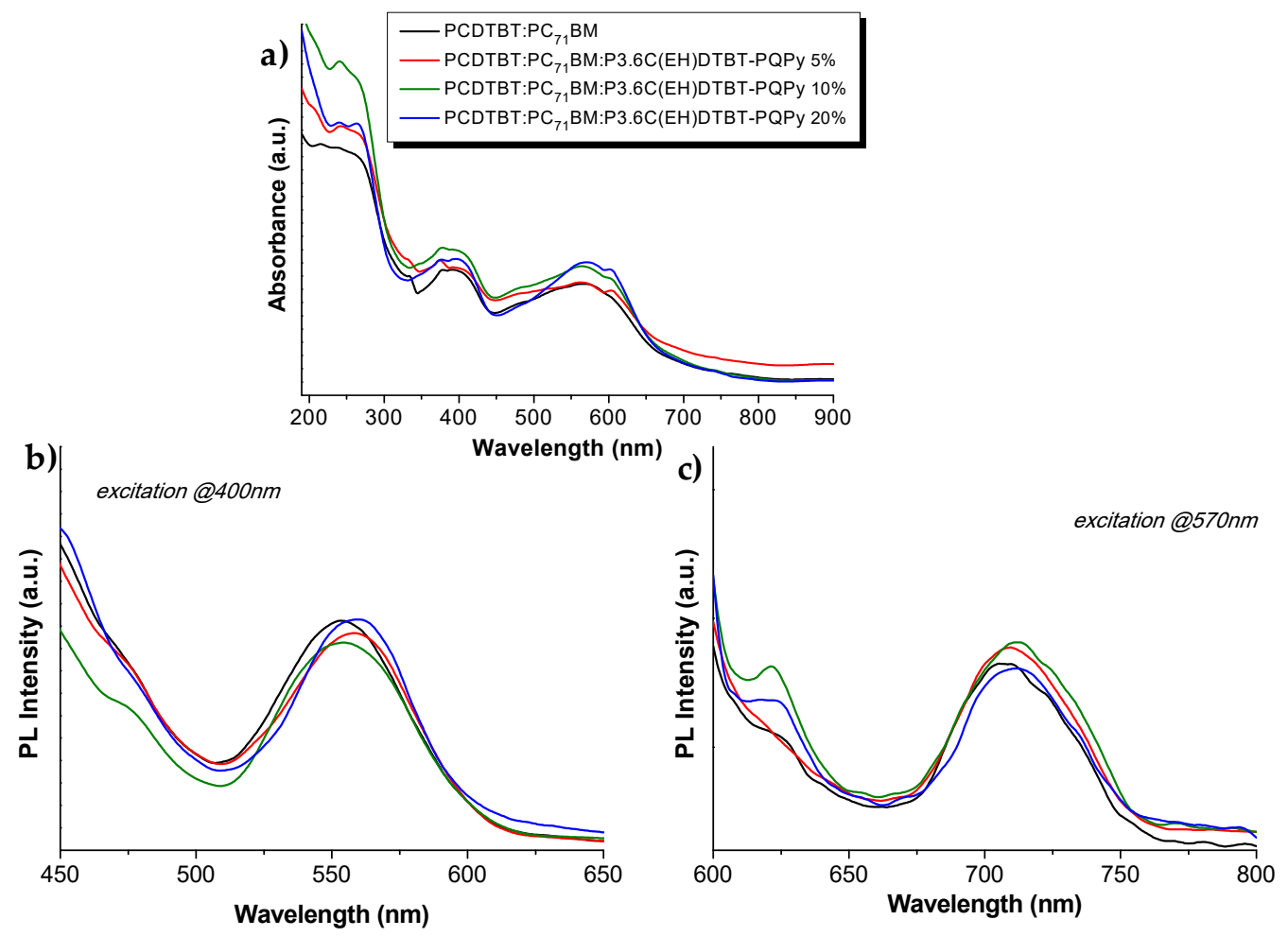

Figure 5. (a) UV-Vis specta; (b) PL spectra upon excitation at $400 \mathrm{~nm}$; and (c) PL spectra upon excitation at 570nm of the PCDTBT:PC 71 BM:P3,6C(EH)DTBT-PQPy blends of spin-coated films.

The UV-Vis and PL spectra of blends 5-7 in spin coated films are shown in Figure 6, where no great differentiations are observed for the blends bearing the copolymer. Upon excitation of the blends at $570 \mathrm{~nm}$, a slightly increased photoluminescent peak is observed, probably due to the interaction of quinoline-pyridine block with the $\mathrm{PC}_{71} \mathrm{BM}$, reducing the quenching phenomenon of the initial donor:acceptor system.

We also chose representative films of blends bearing $10 \%$ of the P3,6C(EH)DTBT-PQPy and the P2,7C(HD)DTBT-PQPy copolymer (blend 3 and 6), which were annealed at $80{ }^{\circ} \mathrm{C}$ in order to investigate potential differences in their optical properties. In any case, no significant effect was observed. 

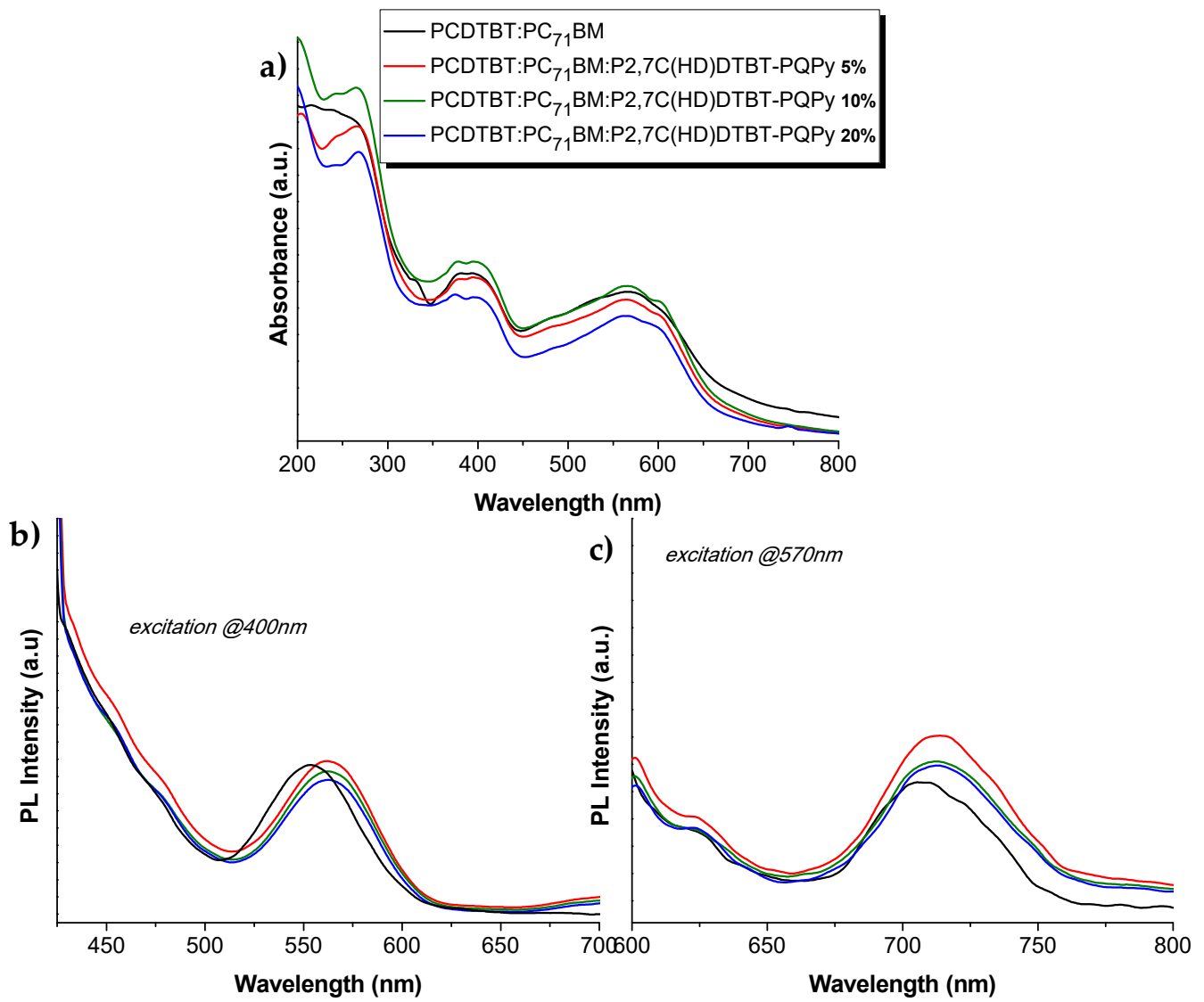

Figure 6. (a) UV-Vis specta; (b) PL spectra upon excitation at $400 \mathrm{~nm}$; and (c) PL spectra upon excitation at 570nm of the PCDTBT:PC 71 BM:P2,7C(HD)DTBT-PQPy blends of spin-coated films.

Thin film morphology of the prepared blends was investigated using transmission electron spectroscopy (TEM), and the images for the blends of PCDTBT:PC ${ }_{71} B M$ with the PCDTBT-PQPy copolymers are presented in this section. $\mathrm{PC}_{71} \mathrm{BM}$ has higher electron density compared to PCDTBT, so electrons are scattered more efficiently from the TEM beam. Thus, the darker regions in the TEM images are regions of phase-separated $\mathrm{PC}_{71} \mathrm{BM}$. In Figure 7, TEM images of blend 1 (PCDTBT:PC ${ }_{71} \mathrm{BM}$ blend) before (Figure $7 \mathrm{a}$ ) and after (Figure $7 \mathrm{~b}$ ) annealing at $80^{\circ} \mathrm{C}$, which is a typical temperature used across the literature for such systems, are presented. A uniform, phase-separated at the nanometer scale morphology is observed, without aggregates, in agreement with literature results for the same system (PCDTBT:PC 71 BM 1:1 from o-DCB solvent) [49].
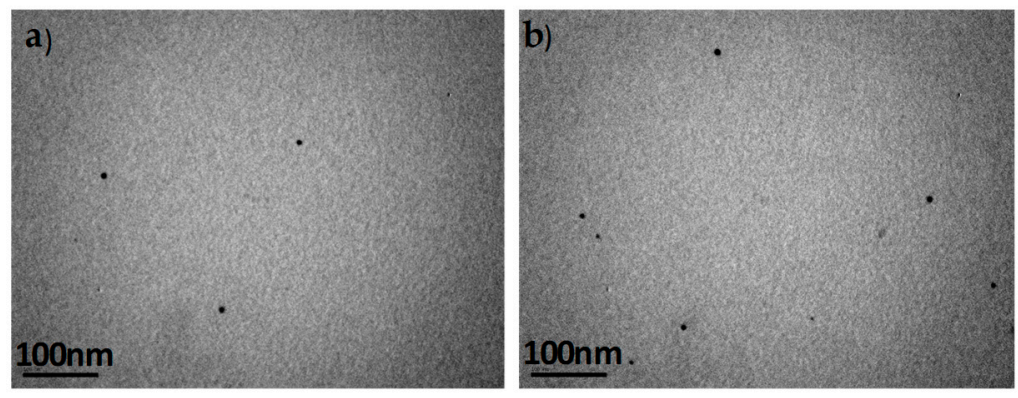

Figure 7. TEM images of a PCDTBT:PC 71 BM 1:1 w/w (a) before and (b) after annealing at $80{ }^{\circ} \mathrm{C}$. The scale bars correspond to $100 \mathrm{~nm}$.

In Figure 8, TEM images for blends 2-4, bearing 5\%, 10\% and 20\% of the P3,6C(EH)DTBT-PQPy copolymer, respectively, before and after annealing at $80{ }^{\circ} \mathrm{C}$ are presented. For blends 2 and 4 , 
bearing $5 \%$ and $20 \%$ of the P3.6C(EH)DTBT-PQPy copolymer, respectively, no alternations are observed before and after annealing. In the case of blend 3, the formation of a homogeneous thin film is observed for the as-drop-casted film. In some areas of the film, and at higher magnifications, some spherical domains are apparent, as depicted in the inset TEM image. After thermal annealing of blend 3, those spherical domains are no longer detectable. In blend 4 , which contains $20 \%$ copolymer, uniform nanophase-separated films are formed, whereas after thermal annealing the morphology of the film is preserved.

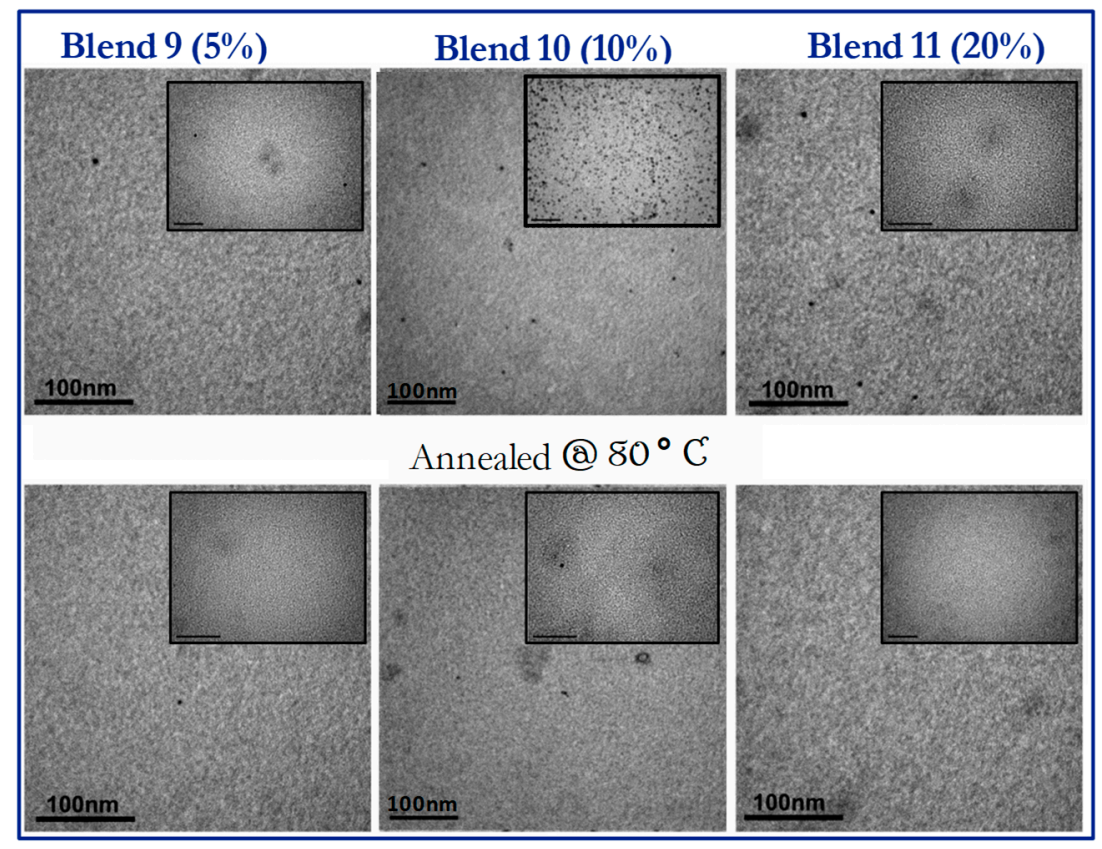

Figure 8. TEM images of a blends 2-4 (PCDTBT:PC 71 BM 1:1 w/w containing 5\%, $10 \%$ and $20 \%$ wt of $\mathrm{P} 3,6 \mathrm{C}(\mathrm{EH}) \mathrm{DTBT}-\mathrm{PQPy}$ without annealing (top images) and after annealing at $80^{\circ} \mathrm{C}$ (bottom images). For the bigger images, the scale bars correspond to $100 \mathrm{~nm}$, while for the inset images, they correspond to $50 \mathrm{~nm}$.

In Figure 9, the TEM images for blends $5-7$, bearing $5 \%, 10 \%$ and $20 \%$ of the $\mathrm{P} 2,7 \mathrm{C}$ (HD)DTBT-PQPy copolymer, respectively, are depicted, before and after annealing at $80{ }^{\circ} \mathrm{C}$. Homogeneous thin films with a more intense nanophase-separated morphology compared to the blends bearing the $\mathrm{P} 3,6 \mathrm{C}(\mathrm{EH}) \mathrm{DTBT}-\mathrm{PQPy}$ copolymer are observed for the as-drop-casted films. Blend 5, bearing 5\% of the P2,7C(HD)DTBT-PQPy copolymer, produced uniform thin films with extended phase separation that becomes more pronounced after annealing at $80{ }^{\circ} \mathrm{C}$, where some spherical domains are formed. When the copolymer ratio is increased to $10 \%$ and $20 \%$ (blends 6 and 7), the films remain uniform and the "spheres" are more detectable. After annealing of the blends, the uniformity of the films is preserved, while the number and size of the "spherical" domains decreases. 


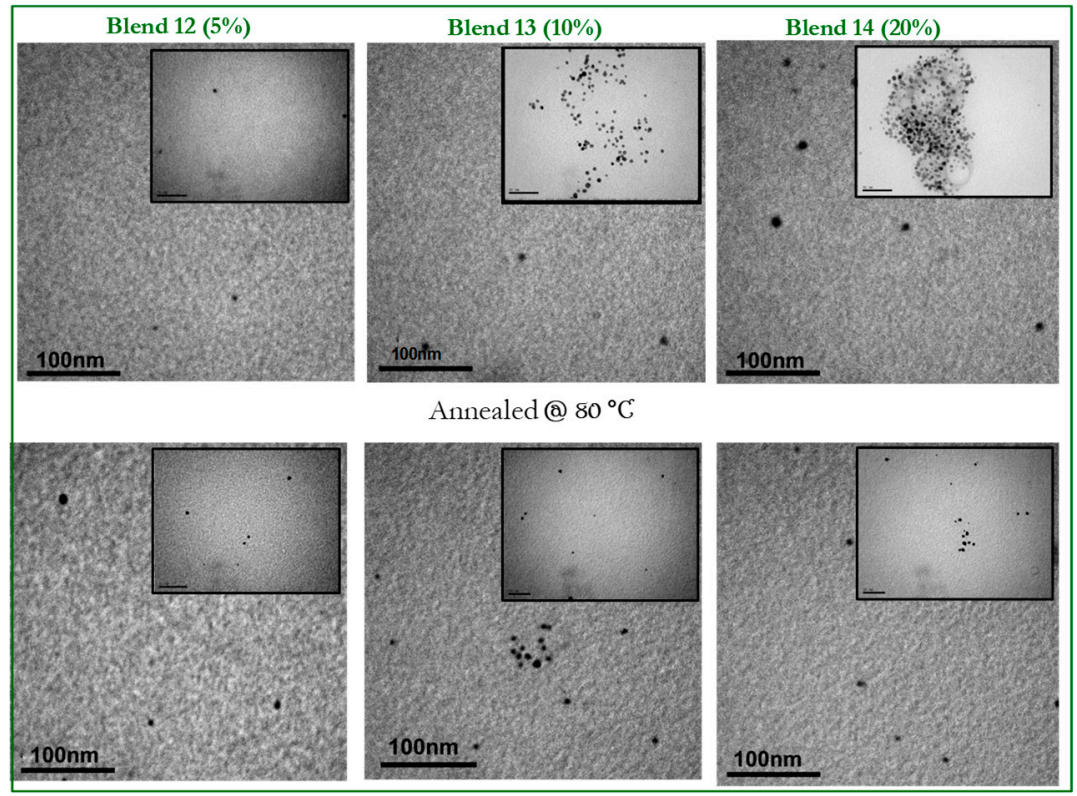

Figure 9. TEM images of blends 5-7 (PCDTBT:PC 71 BM 1:1 w/w containing 5\%, 10\% and 20\% wt of P2,7C(HD)DTBT-PQPy without annealing (top images) and after annealing at $80{ }^{\circ} \mathrm{C}$ (bottom images). For the bigger images, the scale bars correspond to $100 \mathrm{~nm}$, while for the inset images, they correspond to $50 \mathrm{~nm}$.

\subsection{Hybrid Materials from the PCDTBT-P5FQ Copolymer}

The successful synthesis of copolymers consisting of semiconducting PCDTBT and perfluorophenyl-quinoline blocks opens the route for creating hybrid materials to be used as additives in the active layer of OPVs comprising PCDTBT:fullerene active layers, possibly improving the thin layer's nanostructure and stability. Thus, the perfluorophenyl-quinoline units of the P3,6C(EH)DTBT-P5FQ copolymers were transformed to azides using sodium azide in THF (Scheme 3) [26-28,35]. Successful azidation was confirmed using ATR spectroscopy (Figure 11a), where an intense peak around $2100 \mathrm{~cm}^{-1}$ attributed to the azide formation was observed. Thereafter, the azides were employed in a (3+2) cycloaddition reaction with $\mathrm{PC}_{61} \mathrm{BM}$ to provide hybrid semiconducting copolymers. When the perfluorophenyl-quinolines were azidated to a $100 \%$ degree, the final hybrid copolymer was insoluble in common organic solvents. To avoid such insolubility problems, we performed the azidation to a 30\% degree of the perfluorophenyl groups. At this percentage, the obtained hybrid semiconducting copolymers (Scheme 3) were processable in organic solvents, thus enabling their property characterization.
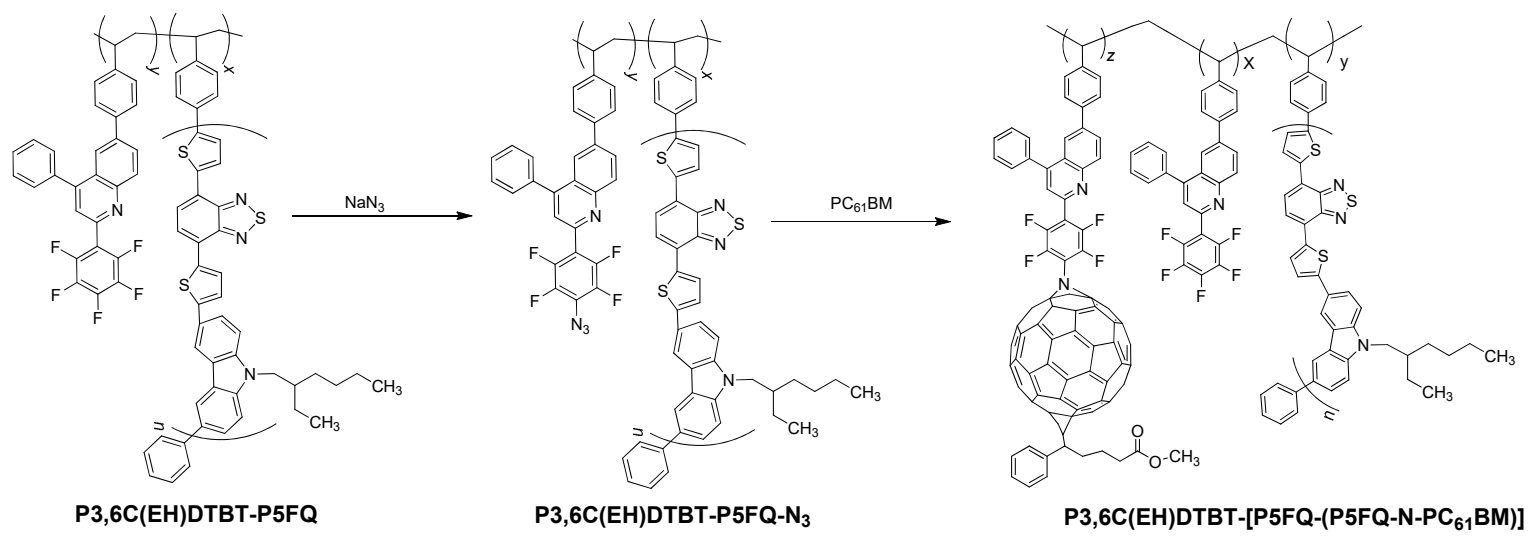

Scheme 3. Synthesis of hybrid material P3,6C(EH)DTBT-(P5FQ-(P5FQ-N-PC 61 BM)). 
After the cycloaddition reaction, the obtained hybrid materials were precipitated, redissolved and precipitated again several times in hexane to remove any unreacted $\mathrm{PC}_{61} \mathrm{BM}$, which was verified each time by TLC using toluene as the mobile face. The ${ }^{1} \mathrm{H}$ NMR spectrum of the hybrid copolymer shown in Figure 10 contains the characteristic proton peaks of $\mathrm{PC}_{61} \mathrm{BM}(\mathrm{a}-\mathrm{d})$, together with those of the quinoline units at 6.5-7.25 ppm and of the carbazole moieties at $4.2 \mathrm{ppm}$, confirming the coexistence of all desired semiconducting and fullerene blocks in the final P3,6C(EH)DTBT-(P5FQ-(P5FQ-N-PC 61 BM)) hybrid.

Additionally, a thorough ATR investigation (Figure 11a) of the purified hybrid material versus the initially obtained crude product of the cycloaddition reaction and the starting copolymer and fullerene precursors, was carried out in order to assess the efficiency of the purification procedure. The hybrid material presented characteristic peaks at 1735, 1428, 1180, 575 and $526 \mathrm{~cm}^{-1}$, which were attributed to the $\mathrm{PC}_{61} \mathrm{BM}$ moieties. During the sequential purification steps of the hybrid copolymer, the ATR spectrum of the intermediates was recorded, and when no further reduction of the fullerene peaks could be observed, we concluded that all unreacted fullerene traces had been successfully removed. The TLC and ATR examination of the intermediates during their purification and of the final hybrid complementarily provided evidence and proof of the hybrid copolymer purity.

Thermogravimetric analysis TGA (Figure 11b) of the initial copolymer and its hybrid derivative with PC $_{61} \mathrm{BM}, \mathrm{P} 3,6 \mathrm{C}(\mathrm{EH}) \mathrm{DTBT}-\left(\mathrm{P} 5 \mathrm{FQ}-\left(\mathrm{P} 5 \mathrm{FQ}-\mathrm{N}-\mathrm{PC}_{61} \mathrm{BM}\right)\right.$ revealed the anticipated higher carbon residue of the hybrid material compared to the initial copolymer. At $800{ }^{\circ} \mathrm{C}$, a $72.35 \%$ residue for the P3,6C(EH)DTBT-(P5FQ-(P5FQ-N-PC 61 BM)) was obtained, whereas a $62.3 \%$ residue was obtained for the initial P3,6C(EH)DTBT-P5FQ. From the TGA, an estimate of $36 \%$ wt of fullerene is incorporated in the hybrid derivative which is in a good agreement with the percentage calculated from the NMR $(34,7 \%)$.

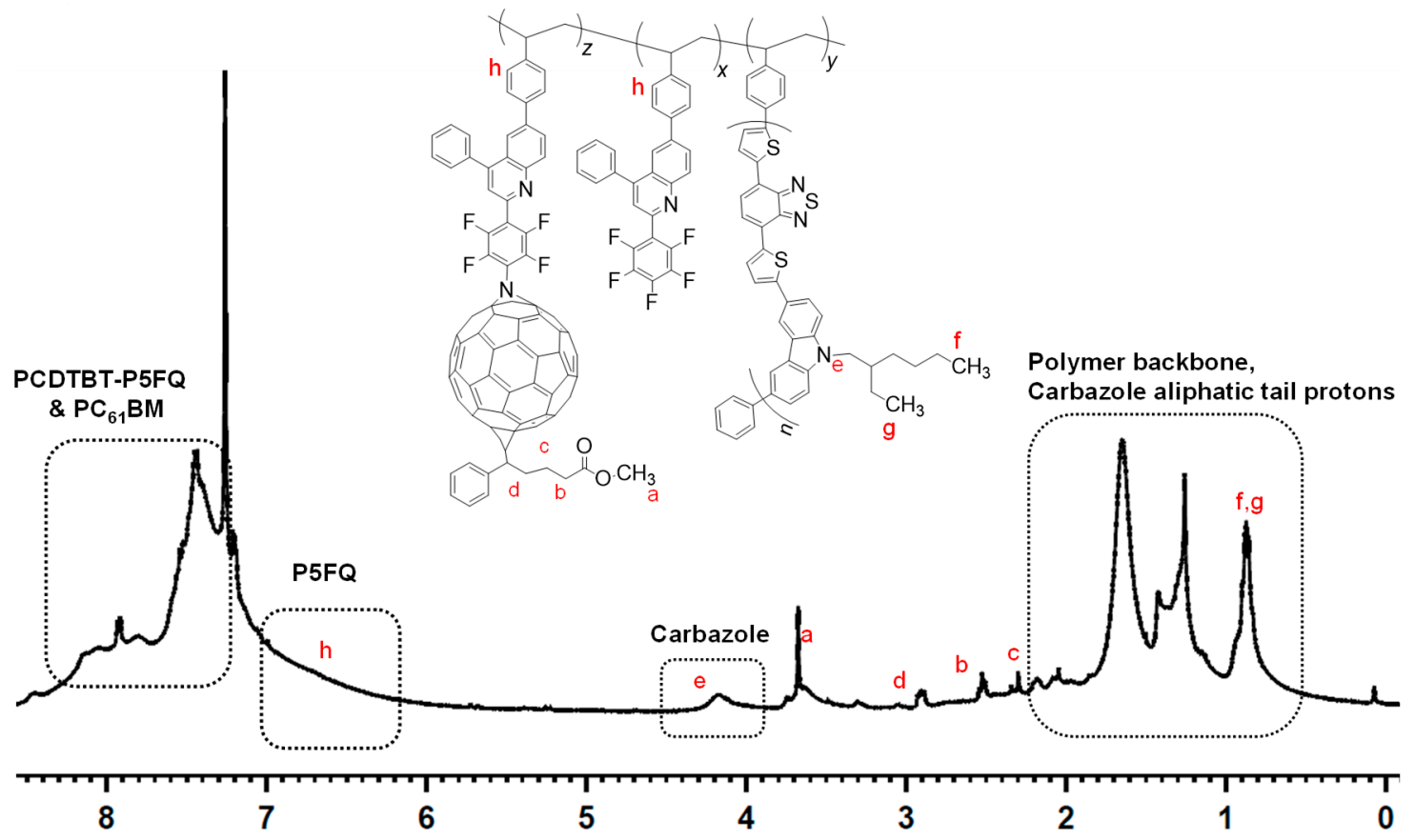

Figure 10. ${ }^{1} \mathrm{H}$ NMR spectrum of $\mathrm{P} 3,6 \mathrm{C}(\mathrm{EH}) \mathrm{DTBT}-\left(\mathrm{P} 5 \mathrm{FQ}-\left(\mathrm{P} 5 \mathrm{FQ}-\mathrm{N}-\mathrm{PC}{ }_{61} \mathrm{BM}\right)\right.$ ) in $\mathrm{CDCl}_{3}$. 

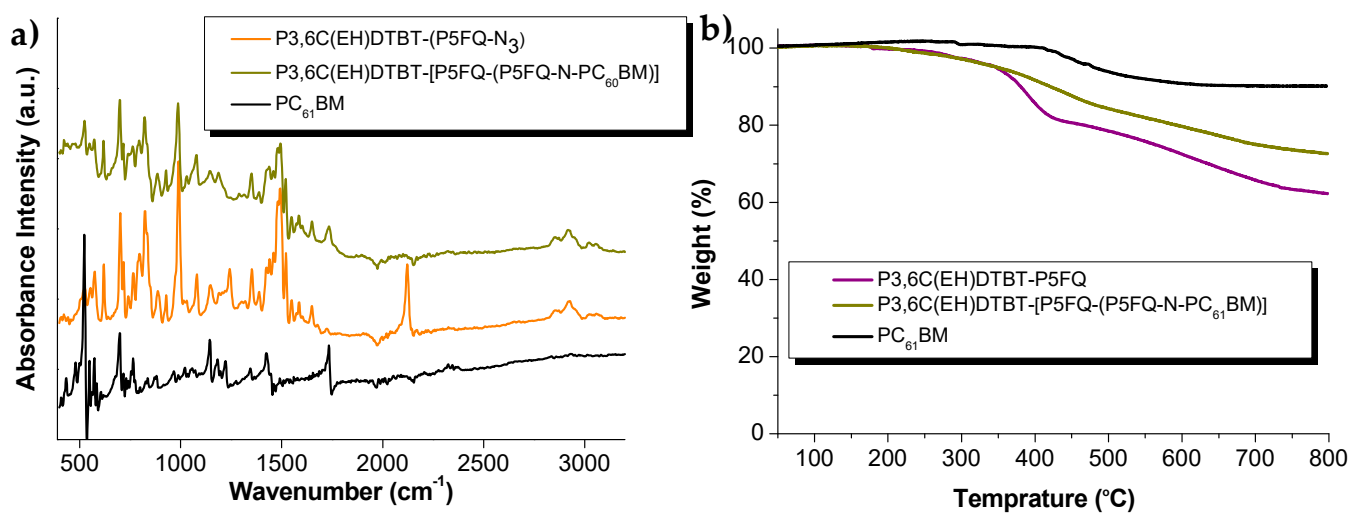

Figure 11. (a) ATR spectra of P3,6C(EH)DTBT-P5FQ, P3,6C(EH)DTBT-(P5FQ-N 3 ) and P3,6C(EH) DTBT-(P5FQ-(P5FQ-N-PC ${ }_{61}$ BM)); (b) TGA thermograms of P3,6C(EH)DTBT-P5FQ, P3,6C(EH) DTBT-(P5FQ-(P5FQ-N-PC 61 BM) and PC $_{61}$ BM.

\subsection{Optical Properties and Morphology Characteriaztion of Hybrid-Material}

The optical properties of the PCDTBT-P5FQ hybrid with $\mathrm{PC}_{61} \mathrm{BM}$ were examined in comparison to the starting copolymer and fullerene materials. In Figure 12, the normalized UV-Vis absorbance spectra of the P3,6C(EH)DTBT-P5FQ and its hybrid derivative, P3,6C(EH)DTBT-(P5FQ-(P5FQ-N-PC 61 BM), are presented. The UV-Vis spectra of the hybrid are a sum of the net counterparts' individual spectra, both in solution and in film form.
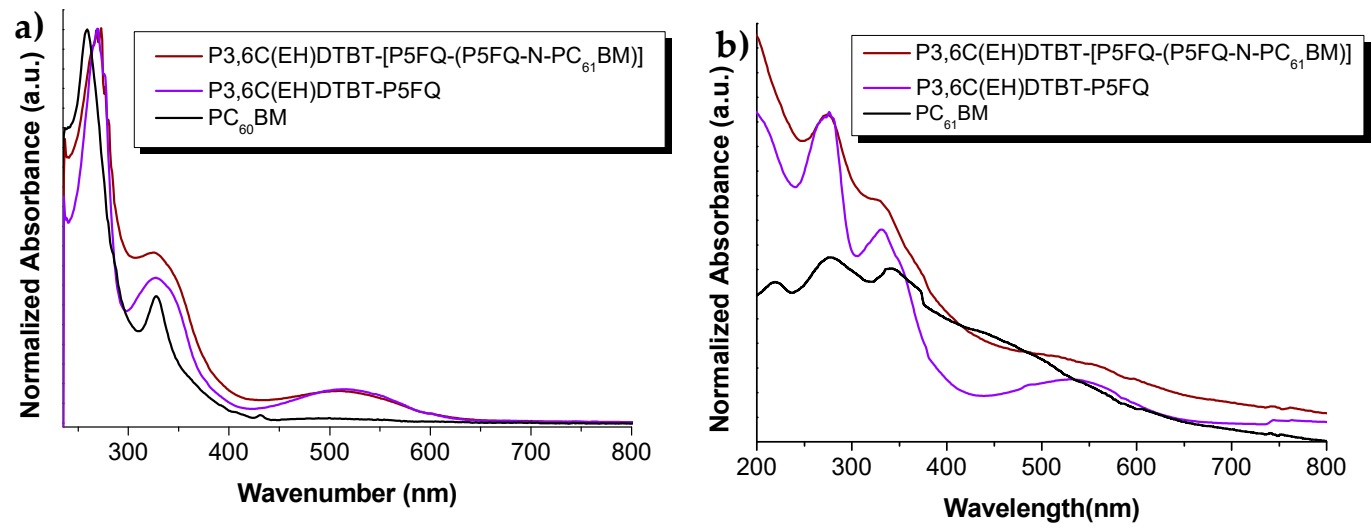

Figure 12. Normalized absorption spectra of $\mathrm{P} 3,6 \mathrm{C}(\mathrm{EH}) \mathrm{DTBT}-\mathrm{P} 5 \mathrm{FQ}, \mathrm{PC}_{61} \mathrm{BM}$ and of their hybrid P3,6C(EH)DTBT-(P5FQ-(P5FQ-N-PC $\left.{ }_{61} \mathrm{BM}\right)$ ) (a) in $o$-DCB solutions; and (b) in thin film form.

Thin film morphology of the P3,6C(EH)DTBT-(P5FQ-(P5FQ-N-PC $\left.{ }_{61} \mathrm{BM}\right)$ was investigated using transmission electron spectroscopy (TEM), and the images are presented in Figure 13a-c, where scale bars correspond to 100, 50 and $20 \mathrm{~nm}$, respectively. The TEM images of the hybrid copolymer using $o-\mathrm{DCB}$, without any thermal treatment of the sample, present smooth, uniform films of favorable nano-scaled morphology without any fullerene aggregates. 

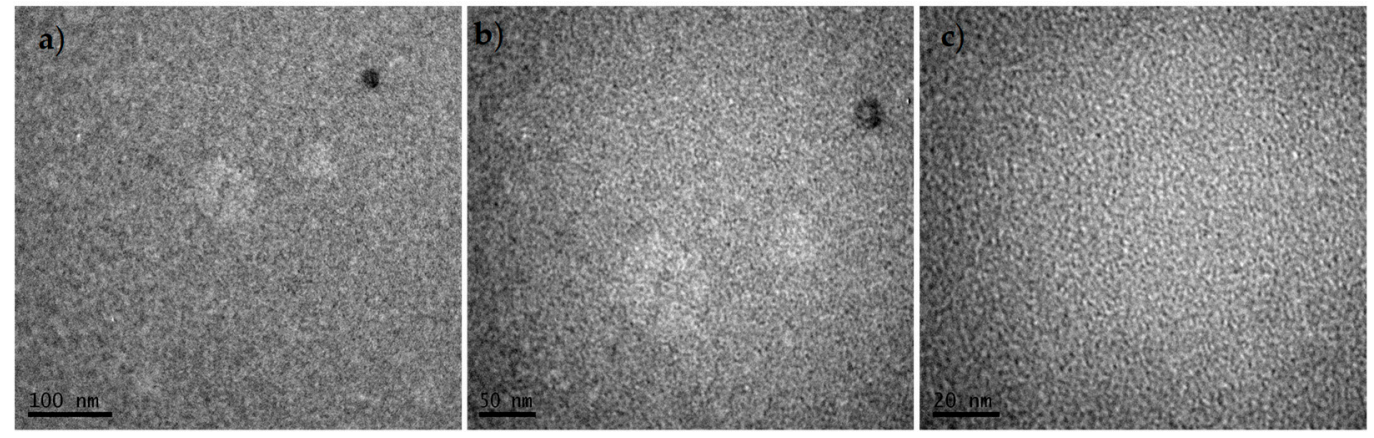

Figure 13. TEM images of $\mathrm{P} 3,6 \mathrm{C}(\mathrm{EH}) \mathrm{DTBT}-\left(\mathrm{P} 5 \mathrm{FQ}-\left(\mathrm{P} 5 \mathrm{FQ}-\mathrm{N}-\mathrm{PC}_{61} \mathrm{BM}\right)\right)$. The scale bars correspond to 100,50 and $20 \mathrm{~nm}$ for figures $(\mathbf{a}),(\mathbf{b})$ and (c), respectively.

\section{Conclusions}

In summary, a typical electron donor PCDTBT, using either the more soluble 3,6-ethylhexyl carbazole or the 2,7-heptadecanyl carbazole group, has been efficiently modified at the $\omega$-end position with double bonds. A modified procedure was employed in order to control the molecular weight, leading to vinyl-functionalized oligomers of PCDTBT that are soluble enough to be used as macromonomers in free radical polymerizations. The vinyl-functionalized macromonomers were copolymerized either with the vinyl quinoline-pyridine monomer, which can interact with fullerene units via non covalent interactions, or with the vinyl perfluorophenyl-quinoline monomer, which can covalently react via $(3+2)$ cycloaddition with fullerene species. The copolymers presented combined optical properties of the two blocks (PCDTBT and quinoline derivative). The influence of the copolymers on the optical properties of electron-donor:fullerene-acceptor mixtures (PCDTBT:PC ${ }_{71} \mathrm{BM}$ ) was also investigated. The morphology of copolymers and hybrids was investigated using transmission electron microscopy (TEM). The copolymers M1 and M2 were added in a typical active layer blend, PCDTBT:PC ${ }_{71} \mathrm{BM}$, in various ratios. Homogeneous thin films were formed, although a more nanophased separated film morphology was observed for the blends bearing the P2,7C(HD)DTBT-PQPy (M2) copolymer. The hybrid material P3,6C(EH)DTBT-(P5FQ-(P5FQ-N-PC $\left.{ }_{61} B M\right)$ ) also formed uniform, nanophased phase-separated film. Based on these results, it can be concluded that the particular "end functionalization" of a well-studied electron donor, such as PCDTBT, is conveniently applicable for the development of functionalized semiconducting electron donors. Reacting these materials with other monomers allows the synthesis of new copolymers and hybrid materials with combined properties, which could be employed as additives of typical polymer-donor:fullerene-acceptor active layer blends for OPVs.

Supplementary Materials: The following are available online at http://www.mdpi.com/2079-4991/9/2/133/s1, Table S1: PCDTBT copolymers nomenclature. Table S2: Preparation of functional PCDTBT oligomers, monomers and conditions employed. Table S3: Abbreviations. Figure S1: ATR spectra of commercial PCDTBT, P3,6C(EH)DTBT-vinyl and P2,7C(HD)DTBT-vinyl CB fractions of the functionalized polymers. The asterisks indicate the $\omega$-end double bonds. Figure S2. ATR spectra of PQPy, P3,6C(EH)DTBT- vinyl and P3,6C(EH)DTBT-PQPy copolymer. Figure S3: GPC Characterization of PCDTBT-P5FQ copolymer and vinyl PCDTBT using the two detectors at 254 and $540 \mathrm{~nm}$. Figure S4: Normalized Absorbance spectra of vinyl PCDTBT macromonomers in o-DCB solutions.

Author Contributions: S.A. and S.K. performed the experiments, analyzed the data and wrote parts of the manuscript. C.A., A.K.A. and J.K.K. supervised the work and wrote parts of the manuscript.

Funding: This research was funded by the "General Secretariat for Research and Technology (GSRT)" and "Hellenic Foundation for Research and Innovation (HFRI)" through the project "1st HFRI Announcement for Doctoral Candidates" Code: 2358.

Acknowledgments: The authors thank D. Vachliotis of the Instrumental Analysis Laboratory, University of Patras for his efforts during the NMR experiments and M. Kollia from the Laboratory of Electron Microscopy and Microanalysis at the University of Patras for the TEM images.

Conflicts of Interest: The authors declare no conflict of interest. 


\section{References}

1. Thompson, B.C.; Fréchet, J.M. Polymer-fullerene composite solar cells. Angew. Chem. Int. Ed. 2008, 47, 58-77. [CrossRef] [PubMed]

2. Gunes, S.; Neugebauer, H.; Sariciftci, N.S. Conjugated polymer-based organic solar cells. Chem. Rev. 2007, 107, 1324-1338. [CrossRef] [PubMed]

3. Logothetidis, S.; Laskarakis, A. Towards the optimization of materials and processes for flexible organic electronics devices. EPJ Appl. Phys. 2009, 46, 12502. [CrossRef]

4. Liu, X.; Wu, Y.; Li, X.; Zhang, W.; Zhao, L.; Wang, H.; Fang, J. CdS-phenanthroline derivative hybrid cathode interlayers for high performance inverted organic solar cells. J. Mater. Chem. A 2016, 4, 297-302. [CrossRef]

5. He, Z.; Xiao, B.; Liu, F.; Wu, H.; Yang, Y.; Xiao, S.; Wang, C.; Russell, P.T.; Cao, Y. Single-junction polymer solar cells with high efficiency and photovoltage. Nat. Photonics 2015, 9, 174-179. [CrossRef]

6. Jagadamma, L.K.; Al-Senani, M.; El-Labban, A.; Gereige, I.; Ngongang Ndjawa, G.O.; Faria, J.C.D.; Kim, T.; Zhao, K.; Cruciani, F.; Anjum, D.H.; et al. Polymer Solar Cells: Polymer Solar Cells with Efficiency $>10 \%$ Enabled via a Facile Solution-Processed Al-Doped ZnO Electron Transporting Layer. Adv. Energy Mater. 2015, 5, 1500204. [CrossRef]

7. Kong, J.; Hwang, I.W.; Lee, K. Top-down approach for nanophase reconstruction in bulk heterojunction solar cells. Adv. Mater. 2014, 26, 6275-6283. [CrossRef]

8. Rogers, J.T.; Schmidt, K.; Toney, M.; Kramer, E.J.; Bazan, G.C. Structural Order in Bulk Heterojunction Films Prepared with Solvent Additives. Adv. Mater. 2011, 23, 2284-2288. [CrossRef]

9. He, Y.; Chen, H.Y.; Hou, J.; Li, Y. Indene-C60 Bisadduct: A New Acceptor for High-Performance Polymer Solar Cells. J. Am. Chem. Soc. 2010, 132, 1377-1382. [CrossRef]

10. Guo, X.; Zhang, M.; Cui, C.; Hou, J.; Li, Y. Efficient Polymer Solar Cells Based on Poly(3-hexylthiophene) and Indene-C60 Bisadduct Fabricated with Non-halogenated Solvents. ACS Appl. Mater. Interfaces 2014, 6, 8190-8198. [CrossRef]

11. Zhang, Y.; Bovill, E.; Kingsley, J.; Buckley, A.R.; Yi, H.; Iraqi, A.; Wang, T.; Lidzey, D.G. PCDTBT based solar cells: On e year of operation under real-world conditions. Sci. Rep. 2016, 6, 21632. [CrossRef] [PubMed]

12. Shim, C.; Kim, M.; Ihn, S.G.; Choi, Y.S.; Kim, Y.; Cho, K. Controlled nanomorphology of PCDTBT-fullerene blends via polymer end-group functionalization for high efficiency organic solar cells. Chem. Commun. 2012, 48, 7206-7208. [CrossRef] [PubMed]

13. Ye, L.; Zhang, S.; Zhao, W.; Yao, H.; Hou, J. Highly Efficient 2D-Conjugated Benzodithiophene-Based Photovoltaic Polymer with Linear Alkylthio Side Chain. Chem. Mater. 2014, 26, 3603-3605. [CrossRef]

14. Stenta, C.; Molina, D.; Viterisi, A.; Montero-Rama, M.P.; Pla, S.; Cambarau, W.; Fernández-Lázaro, F.; Palomares, E.; Marsal, L.F.; Sastre-Santos, A. Diphenylphenoxy-Thiophene-PDI Dimers as Acceptors for OPV Applications with Open Circuit Voltage Approaching 1 Volt \%. Nanomaterials 2018, 8, 211. [CrossRef]

15. Li, Y.N.; Vamvounis, G.; Holdcroft, S. Facile functionalization of poly(3-alkylthiophene)s via electrophilic substitution. Macromolecules 2001, 34, 141-143. [CrossRef]

16. Kim, I.K.; Jo, J.H.; Yun, J.-H. Morphology-Controlled High-Efficiency Small Molecule Organic Solar Cells without Additive Solvent Treatment. Nanomaterials 2016, 6, 64. [CrossRef] [PubMed]

17. Lu, Z.; Liu, W.; Li, J.; Fang, T.; Li, W.; Zhang, J.; Feng, F.; Li, W. The Influence of Fluorination on Nano-Scale Phase Separation and Photovoltaic Performance of Small Molecular/PC 71 BM Blends. Nanomaterials 2016, 6, 80. [CrossRef] [PubMed]

18. Vahdani, P.; Li, X.; Zhang, C.; Holdcroft, S.; Frisken, B.J. Morphological characterization of a new low-bandgap thermocleavable polymer showing stable photovoltaic properties. J. Mater. Chem. A 2016, 4, 10650-10658. [CrossRef]

19. Seibers, Z.D.; Le, T.P.; Lee, Y.; Gomez, E.D.; Kilbey, S.M. Impact of Low Molecular Weight Poly(3-hexylthiophene)s as Additives in Organic Photovoltaic Devices. ACS Appl. Mater. Interfaces 2018, 10, 2752-2761. [CrossRef]

20. Karagiannidis, P.G.; Georgiou, D.; Pitsalidis, C.; Laskarakis, A.; Logothetidis, S. Evolution of vertical phase separation in P3HT:PCBM thin films induced by thermal annealing. Mater. Chem. Phys. 2011, 129, 1207-1213. [CrossRef] 
21. Kim, Y.; Cook, S.; Kirkpatrick, J.; Nelson, J.; Durrant, J.R.; Bradley, D.D.C.; Giles, M.; Heeney, M.; Hamilton, R.; McCulloch, I. Effect of the End Group of Regioregular Poly(3-hexylthiophene) Polymers on the Performance of Polymer/Fullerene Solar Cells. J. Phys. Chem. 2007, 111, 8137-8141. [CrossRef]

22. Kim, J.S.; Lee, Y.; Lee, J.H.; Park, J.H.; Kim, J.K.; Cho, K. High-Efficiency Organic Solar Cells Based on End-Functional-Group-Modified Poly(3-hexylthiophene). Adv. Mater. 2010, 22, 1355-1360. [CrossRef] [PubMed]

23. Kim, H.J.; Han, A.-R.; Cho, C.-H.; Kang, H.; Cho, H.-H.; Lee, M.Y.; Fréchet, J.M.J.; Oh, J.H.; Kim, B.J. Solvent-Resistant Organic Transistors and Thermally Stable Organic Photovoltaics Based on Cross-linkable Conjugated Polymers. Chem. Mater. 2012, 24, 215-221. [CrossRef]

24. Yassara, A.; Miozzoa, L.; Girondaa, R.; Horowitz, G. Rod-coil and all conjugated block copolymers for photovoltaic applications. Prog. Polym. Sci. 2013, 38, 791-844. [CrossRef]

25. Kallitsis, J.K.; Anastasopoulos, C.; Andreopoulou, A.K. Functional semiconductors targeting copolymer architectures and hybrid nanostructures. MRS Commun. 2015, 5, 365-382. [CrossRef]

26. Kakogianni, S.; Andreopoulou, A.K.; Kallitsis, J.K. Synthesis of Polythiophene-Fullerene Hybrid Additives as Potential Compatibilizers of BHJ Active Layers. Polymers 2016, 8, 440. [CrossRef]

27. Kakogianni, S.; Lebedeva, M.; Paloumbis, G.; Andreopoulou, A.K.; Porfyrakis, K.; Kallitsis, J.K. Semiconducting End-Perfluorinated P3HT-Fullerenic Hybrids as Potential Additives for P3HT/IC 70 BA blends. RSC Adv. 2016, 6, 100. [CrossRef]

28. Sygellou, L.; Kakogianni, S.; Andreopoulou, A.K.; Theodosiou, K.; Leftheriotis, G.; Kallitsis, J.K.; Siokou, A.E. Evaluation of the electronic properties of perfluorophenyl functionalized quinolines and their hybrids with carbon nanostructures. Phys. Chem. Chem. Phys. 2016, 18, 5. [CrossRef]

29. Yuan, K.; Chen, L.; Chen, Y. Nanostructuring compatibilizers of block copolymers for organic Photovoltaics. Polym. Int. 2014, 63, 593-606. [CrossRef]

30. Sartorio, C.; Campisciano, V.; Chiappara, C.; Cataldo, S.; Scopelliti, M.; Gruttadauria, M.; Giacalone, F.; Pignataro, B. Enhanced Power-Conversion Efficiency in Organic Solar Cells Incorporating Copolymeric Phase-Separation Modulators. J. Mater. Chem. A 2018, 6, 3884-3894. [CrossRef]

31. Laiho, A.; Ras, R.H.A.; Valkama, S.; Ruokolainen, J.; Österbacka, R.; Ikkala, O. Control of Self-Assembly by Charge-Transfer Complexation between C60 Fullerene and Electron Donating Units of Block Copolymers. Macromolecules 2006, 39, 7648-7653. [CrossRef]

32. Renaud, C.; Mougnier, S.-J.; Pavlopoulou, E.; Brochon, C.; Fleury, G.; Deribew, D.; Portale, G.; Cloutet, E.; Chambon, S.; Vignau, L.; et al. Block Copolymer as a Nanostructuring Agent for High-Efficiency and Annealing-Free Bulk Heterojunction Organic Solar Cells. Adv. Mater. 2012, 24, 2196-2201. [CrossRef] [PubMed]

33. Hsu, S.; Chen, C.; Cheng, Y.; Wei, K. New Carbazole-Based Conjugated Polymers Containing Pyridylvinyl Thiophene Units for Polymer Solar Cell Applications: Morphological Stabilization Through Hydrogen Bonding. J. Polym. Sci. Part A Polym. Chem. 2011, 49, 603-611. [CrossRef]

34. Chen, H.; Chen, J.; Yin, W.; Yu, X.; Shao, M.; Xiao, K.; Hong, K.; Pickel, D.L.; Kochemba, W.M.; Kilbey, S.M., II; Dadmun, M. Correlation of polymeric compatibilizer structure to its impact on the morphology and function of P3HT:PCBM bulk heterojunctions. J. Mater. Chem. A 2013, 1, 5309-5319. [CrossRef]

35. Kakogianni, S.; Kourkouli, S.N.; Andreopoulou, A.K.; Kallitsis, J.K. A versatile approach for creating hybrid semiconducting polymer-fullerene architectures for organic electronics. J. Mater. Chem. A 2014, 2, 8110-8117. [CrossRef]

36. Kourkouli, S.N.; Siokou, A.; Stefopoulos, A.A.; Ravani, F.; Plocke, T.; Müller, M.; Maultzsch, J.; Thomsen, C.; Papagelis, K.; Kallitsis, J.K. Electronic Properties of Semiconducting Polymer-Functionalized Single Wall Carbon Nanotubes. Macromolecules 2013, 46, 2590-2598. [CrossRef]

37. Stefopoulos, A.A.; Kourkouli, S.N.; Economopoulos, S.; Ravani, F.; Andreopoulou, A.K.; Papagelis, K.; Siokou, A.; Kallitsis, J.K. Polymer and hybrid electron accepting materials based on a semiconducting perfluorophenylquinoline. Macromolecules 2010, 43, 4827-4828. [CrossRef]

38. Giannopoulos, P.; Raptis, D.; Theodosiou, K.; Andreopoulou, A.K.; Anastasopoulos, C.; Dokouzis, A.; Leftheriotis, G.; Lianos, P.; Kallitsis, J.K. Organic Dyes End-Capped with Perfluorophenyl Anchors: Synthesis, Electrochemical Properties and Assessment of Sensitization Capacity of Titania Photoanodes. Dyes Pigments 2018, 148, 167-179. [CrossRef] 
39. Schimperna, G.; Bianchi, G. Process for the preparation of benzohetero [1,3]-diazole compounds disubstituted with heteoaryl groups. U.S. Patent WO2013021315 A1, 14 February 2013.

40. Zhang, C. Process for preparing a 4,7-bis(5-halothien-2-yl)-2,1,3-benzothiadiazole and a precursor therefor. U.S. Patent 2004/0229925 A1, 18 November 2004.

41. Blouin, N.; Michaud, A.; Leclerc, M. A Low-Bandgap Poly(2,7-Carbazole) Derivative for Usein High-Performance Solar Cell. Adv. Mater. 2007, 19, 2295-2300. [CrossRef]

42. Li, J.; Meng, Q.; Kim, J.; Lee, Y. A Thiophene, Benzothiadiazole, and Carbazole-Based Copolymer Synthesis and Characterization. Bull. Korean Chem. Soc. 2009, 30, 951-954. [CrossRef]

43. Berton, N.; Ottone, C.; Labet, V.; Bettignies, R.; Bailly, S.; Grand, A.; Morell, C.; Sadki, S.; Chandezon, F. New Alternating Copolymers of 3,6-Carbazoles and Dithienylbenzothiadiazoles: Synthesis, Characterization, and Application in Photovoltaics. Macromol. Chem. Phys. 2011, 212, 2127-2141. [CrossRef]

44. Coulson, D.R.; Satek, L.C.; Grim, S. Tetrakis(triphenylphosphine)palladium(0). In Inorganic Syntheses; Cotton, F.A., Ed.; John Wiley \& Sons, Inc.: Hoboken, NJ, USA, 1972; Volume 13, ISBN 9780470132449.

45. Kim, J.; Kwon, Y.S.; Shin, W.S.; Moon, S.J.; Park, T. Carbazole-Based Copolymers: Effects of Conjugation Breaks and Steric Hindrance. Macromolecules 2011, 44, 1909-1919. [CrossRef]

46. Fu, Y.; Kim, J.; Siva, A.; Shin, W.S.; Moon, S.J.; Park, T. Parameters Influencing the Molecular Weight of 3,6-Carbazole-Based D-p-A-Type Copolymers. J. Polym. Sci. A Polym. Chem. 2011, 49, 4368-4378. [CrossRef]

47. Svensson, M.; Zhang, F.; Veenstra, S.C.; Verhees, W.J.H.; Hummelen, J.C.; Kroon, J.M.; Inganäs, O.; Andersson, M.R. High-Performance Polymer Solar Cells of an Alternating Polyfluorene Copolymer and a Fullerene Derivative. Adv. Mater. 2003, 15, 988-991. [CrossRef]

48. Kingsley, J.W.; Marchisio, P.P.; Yi, H.; Iraqi, A.; Kinane, C.J.; Langridge, S.; Thompson, R.L.; Cadby, A.J.; Pearson, A.J.; Lidzey, D.G.; et al. Molecular weight dependent vertical composition profiles of PCDTBT:PC71BM blends for organic photovoltaics. Sci. Rep. 2014, 4, 5286. [CrossRef] [PubMed]

49. Park, S.H.; Roy, A.; Beaupre, S.; Cho, S.; Coates, N.; Moon, J.S.; Moses, D.; Leclerc, M.; Lee, K.; Heeger, A.J. Bulk heterojunction solar cells with internal quantum efficiency approaching $100 \%$. Nat. Photonics 2009, 3, 297-302. [CrossRef] 